\title{
Sujeitos de papel: sobre a materialização de pessoas transexuais e a regulação do acesso a direitos*
}

Lucas Freire**

\section{Resumo}

Um conjunto de documentos - lista de testemunhas, fotografias, relatórios, laudos etc. - se encontra nas pastas de pessoas transexuais que demandam a alteração do nome e/ou sexo no registro civil e são atendidas no Núcleo de Defesa da Diversidade Sexual e Direitos Homoafetivos da Defensoria Pública do Rio de Janeiro. Este artigo tem por objetivo refletir sobre como esses papéis são capazes de produzir a realidade e dar materialidade aos sujeitos desses processos, permitindo que certos direitos possam ser acessados somente por aqueles que são considerados "verdadeiramente transexuais".

Palavras-chave: Materialidade, Documentos, Transexualidade, Requalificação Civil, Direitos.

* Recebido em 16 de novembro de 2015, aceito em 18 de agosto de 2016. Versões anteriores deste texto foram apresentadas nos GTs "Antropologia, Burocracia e Documentos" do IV ENADIR e "Sexualidade e Gênero: sujeitos, práticas, regulações" do $39^{\circ}$ Encontro Anual da ANPOCS. Agradeço imensamente por todas as sugestões e comentários feitos por coordenadores, debatedores e expectadores nestas ocasiões.

** Doutorando do Programa de Pós-Graduação em Antropologia Social do Museu Nacional da Universidade Federal do Rio de Janeiro (PPGAS/MN/UFRJ). lucas.mfreire@hotmail.com 
Subjects of Paper: on the Materialization of Transsexual People and the Regulation of Access to Rights

\begin{abstract}
A set of documents - list of witnesses, photographs, records, reports etc. - is found inside the archives of transsexual people that require a change of name and/or sex in the civil registry and are attended in the Defense Center of Sexual Diversity and "Homoaffective Rights" of the State Public Defender of Rio de Janeiro. This paper aims to reflect on how these documents are capable of producing reality and giving materiality to the subjects of these processes, allowing certain rights to be accessed only by those who are considered "true transsexuals".
\end{abstract}

Keywords: Materiality, Documents, Transsexuality, Civil Requalification, Rights. 


\section{Introdução}

O Núcleo de Defesa da Diversidade Sexual e Direitos Homoafetivos (NUDIVERSIS) da Defensoria Pública Geral do Estado do Rio de Janeiro (DPGE-RJ) é uma instituição pública "especializada" em "acolher" as demandas judiciais e prestar assistência e aconselhamento jurídico gratuitos a chamada "população LGBT" (Aguião, 2014), isto é, lésbicas, gays, bissexuais, travestis e transexuais, residente no Estado do Rio de Janeiro. Por se tratar de um núcleo de primeiro atendimento, sua função é atuar, ao menos oficialmente, apenas em uma etapa préprocessual, ou seja, produzir petições inicias ${ }^{1}$ e reunir todas as "provas" necessárias para que os pedidos feitos sejam julgados procedentes.

Entre os meses de fevereiro e julho de 2014, acompanhei as rotinas de trabalho das funcionárias ${ }^{2}$ do núcleo tanto nos atendimentos ao público quanto em seus expedientes internos. Durante esse período, busquei atentar para os procedimentos por meio dos quais as pessoas transexuais eram produzidas enquanto "sujeitos de direitos" 3 no cotidiano da administração pública,

1 Petição inicial é o nome dado ao documento protocolado em um órgão competente do Poder Judiciário para dar início a um processo judicial. Por meio dela, o caso é construído com a descrição dos motivos que levaram a/o autora/or da ação a solicitar algo e dos argumentos que justificam sua demanda.

2 Na época da pesquisa, a estrutura profissional do NUDIVERSIS era composta por uma defensora pública, uma assessora, uma funcionária técnicaadministrativa e duas estagiárias. $\mathrm{O}$ fato de todas as profissionais em atuação na instituição serem mulheres é extremamente importante para compreender uma espécie de "generificação do cuidado" que fundamenta a própria necessidade de existência de um núcleo especializado no atendimento da "população LGBT". Entretanto, devido aos limites deste artigo, essa questão não será aprofundada. Para uma elaboração mais densa desse ponto, ver Freire (2015a).

3 A noção de "sujeitos de direitos" aqui utilizada é inspirada nas discussões realizadas por Schritzmeyer (2012) sobre como se constitui a demanda por "direito aos direitos" e, mais especificamente, pelas reflexões de Vianna (2012) acerca da consolidação não só de um conjunto de reivindicações colocadas sob a rubrica dos "direitos sexuais", mas também dos "sujeitos" de tais "direitos". Como será discutido ao longo deste artigo, uma das principais questões que se 
principalmente em relação à demanda por requalificação civil, ou alteração do nome e/ou sexo no registro civil. ${ }^{4}$ Além desse acompanhamento, que pode ser considerado uma forma mais usual de realizar uma etnografia, dediquei parte de minha pesquisa à análise dos documentos que compõem as pastas das/os "assistidas/os" - categoria utilizada para designar as/os usuárias/os dos serviços da Defensoria Pública.

Antes de mais nada, é preciso destacar que essas pastas são constituídas por dois tipos distintos de "papéis": as folhas que estão devidamente presas à pasta, numeradas e carimbadas por algum funcionário da DPGE-RJ, ou seja, os "documentos", com seus poderes de verdade específicos; e os outros papéis que são entregues pelas/os assistidas/os e permanecem "soltos" no interior das pastas, dentre os quais se encontram matérias de jornais, crachás de trabalho, ingressos de eventos etc. Os primeiros, aqueles que estão registrados e adequadamente apensados à pasta, são sempre anexados à petição inicial; já os últimos, podem ou não vir a figurar como elementos complementares para a comprovação de algo. Por conta das questões que pretendo abordar, concentro-me aqui no primeiro tipo de papel descrito, ou seja, nos documentos que adquirem um status de prova nas ações de requalificação civil, nos papéis, que em acúmulo, organização $e$ arquivamento, funcionam como elementos materiais que produzem os sujeitos da administração pública.

No caso dos pedidos de requalificação civil, uma espécie de "etnografia dos papéis" se justifica na medida em que, como

encontram em jogo quando falo sobre os processos que produzem as pessoas transexuais enquanto "sujeitos de direitos" é uma espécie de dimensão moral da "legitimidade" tanto dos indivíduos quanto de seus anseios.

4 Outros pedidos e reclamações feitos pelas pessoas transexuais estavam relacionados à falta ou ao não acesso aos medicamentos indicados como terapêuticos para a transexualidade - geralmente hormônios e/ou inibidores de hormônios; ou ainda, reclamações sobre serviços de saúde prestados pelos programas transexualizadores, como o longo tempo de espera para a marcação de consultas, a falta de vaga em ambulatórios, a não previsão de realização da cirurgia transgenitalizadora, o não respeito ao uso do nome social etc. 
apontado por Ferreira (2011), nos contextos de pesquisa em instituições públicas, os documentos figuram como "artefatos etnográficos" por meio dos quais é possível acessar os modos como o cotidiano administrativo das repartições é arquivado. Ademais, podemos pensar os processos burocráticos da administração pública que envolvem a etapa pré-processual de alteração de nome e sexo de pessoas transexuais como uma espécie de fabricação contínua de papéis, uma vez que, ao chegar no NUDIVERSIS, a/o assistida/o precisa entregar um conjunto de papéis (cópias dos documentos civis, lista de testemunhas $e$ fotografias), que gerarão um papel (Relatório de Primeiro Atendimento) para que se possa solicitar outros papéis (Certidões dos Ofícios de Registro de Distribuição e Estudo Social), os quais servirão de base para a produção de mais papéis (a petição inicial) que terão por objetivo argumentar em favor da aquisição de novos papéis (os documentos civis alterados). Dito de outro modo, esses processos de Estado se materializam nesse complexo de papéis de diversos tipos que compõem não somente as pastas das/os assistidas/os da Defensoria Pública, mas as/os acompanham durante toda a vida.

\section{Dos documentos que fazem pessoas: um espelho da realidade?}

O Presidente da Câmara e relator do recurso, Desembargador $[\mathrm{x}]$, votou pelo provimento do apelo do requerente destacando-se na motivação do voto as ponderações sobre o alcance do registro civil de uma pessoa e se deve o mesmo refletir uma realidade apenas biológica. O fato é que, na sua forma exterior, na sua aparência $e$ em confronto com essa aparência, o registro civil do apelante não reflete a realidade. Por não refletir a realidade é que ele incute terceiros em erro, que abalam o equilíbrio jurídico (Modelo de petição inicial, grifos meus).

Existe uma extensa lista de documentos que são considerados como necessários para que a ação de requalificação civil seja instaurada. No âmbito da qualificação civil, é preciso 
apresentar cópias da Certidão de Nascimento, da Carteira de Identidade, do CPF, do Título de Eleitor, do Certificado de Reservista (para aqueles cujo sexo de registro é masculino), do Passaporte (caso tenha), da Carteira de Habilitação (caso tenha), da Carteira de Trabalho, do contracheque e/ou outro comprovante de renda, do comprovante de residência e dos diplomas de escolaridade e/ou cursos profissionalizantes. Além disso, são solicitados outros documentos que possuem poderes de produção de verdade distintos uns dos outros. Dentre eles se encontram: uma relação de ao menos três testemunhas, laudos psicológicos e psiquiátricos que atestem a transexualidade, atestado médico de realização da cirurgia de transgenitalização (nos poucos casos em que isso se aplica), exames médicos, receitas de hormônios, estudo social emitido por psicólogos e assistentes sociais servidores da Defensoria Pública, certidões de nada consta dos Ofícios de Registro de Distribuição (ORD) e algumas fotografias.

Como pode ser depreendido a partir do trecho citado no início deste tópico, parte da argumentação apresentada pelas operadoras do Direito para que a alteração do nome e/ou sexo nos documentos civis seja concedida se baseia na função legal dos documentos de registro civil de "refletir a realidade". Assim, defende-se que, uma vez que a pessoa se apresenta por um nome $e$ "possui a aparência" do sexo oposto ao que consta no registro, tanto o nome quanto o "sexo" devem ser "corrigidos" para que cumpram corretamente sua obrigação. Tomando como pressuposto a ideia de Vianna (2014) acerca do potencial dos documentos para produzir mundos sociais, pretendo problematizar a premissa de que um documento deve ser "espelho da realidade" através da sua inversão. Ou seja, considero que, ao invés de descrever ou refletir a realidade, essas certidões, relatórios, laudos, atestados, fotografias etc. funcionam de modo a produzir a realidade e dar materialidade aos sujeitos que figuram nesses processos.

Nos processos de requalificação civil de pessoas transexuais, uma das principais dimensões do sujeito constituída por meio dos 
documentos diz respeito ao sexo/gênero. Se, como propõe Butler (2003), o sexo é uma categoria fundamental da inteligibilidade das figuras humanas, faz sentido pensar na centralidade do registro documental do sexo, tendo em vista que não é possível existir "cidadão sem sexo". Essa impossibilidade se dá na medida em que determinados "direitos" e "deveres" dos "cidadãos brasileiros" - tais como a obrigatoriedade do alistamento militar $e$ a idade mínima para a aposentadoria convencional - são diferenciados com base no registro da masculinidade ou feminilidade dos sujeitos.

Segundo um discurso diversas vezes reiterado pelas funcionárias do NUDIVERSIS, os documentos exigidos às pessoas transexuais que solicitam a requalificação civil servem para comprovar - e nesse processo sedimentar determinadas "verdades" - uma série de coisas: a transexualidade, a condição de sofrimento, a identidade de gênero $e$, principalmente, a legitimidade de sua demanda. ${ }^{5}$

A necessidade de apresentação de provas está ligada a dois fatores: por um lado, o caráter formal do "Direito Objetivo" marca de modos de governo baseados na burocracia - coloca como prerrogativa do Poder Judiciário julgar objetiva $e$ imparcialmente qualquer assunto que lhe seja apresentado (Weber, 1999). Em outras palavras, esse formalismo jurídico é consequência de um Direito que prevê uma suposta racionalidade administrativa. Nesse sentido, as decisões judicias do Direito moderno são tomadas com base em um processo formal e em determinadas "provas racionais e objetivas": documentos, testemunhas, dentre outras.

\footnotetext{
${ }^{5}$ Ressalvo que a exigência de todos esses documentos se encontra inserida em um quadro de imprevisibilidade normativa e legal no que diz respeito aos pedidos de requalificação civil. Uma vez que não existe uma lei de identidade de gênero que padronize os procedimentos, a alteração do nome e/ou sexo no registro civil demanda um processo judicial a ser julgado em um tribunal, o que pode dar liberdade para que os juízes requeiram outros documentos ou não exijam algum.
} 
Por outro, essas provas se fazem necessárias em um contexto no qual impera uma "lógica da suspeição" na administração pública, isto é, existe uma presunção de culpa que implica o emprego de uma série de procedimentos que visa comprovar a inocência de quem se põe sob o escrutínio do Estado. Para Miranda (2012), a imprescindibilidade das provas está ligada a uma espécie de tradição do Estado brasileiro "de se colocar num legalismo formalístico caracterizado pela necessidade de documentos com fé pública, em que cabe ao cidadão provar quem é, o que faz e quais suas intenções" (Miranda, 2012:280).

Nos processos de requalificação civil administrados pelo NUDIVERSIS, tal lógica de suspeição se torna evidente quando as profissionais do núcleo afirmam que os documentos requisitados funcionam como provas para afastar a constante suspeita de que as pessoas solicitam a alteração do registro civil para escapar de julgamento e/ou condenação por conta de algum crime, dívida etc.

A noção de prova está intimamente conectada com a ideia de verdade, pois sua função é, obviamente, provar a veracidade de uma dada afirmação. O ato de provar nada mais é que atestar, confirmar, comprovar, certificar a autenticidade de um fato ou alegação. Ou ainda, provar não é senão uma forma de "demonstrar a realidade". Verdade e realidade podem então ser compreendidas como noções inseparáveis, sinônimas e quase indistinguíveis. Se algo é considerado como verdadeiro, ele é imediatamente encarado como real e vice-versa.

Se os documentos são considerados provas $e$ as provas criam a realidade, passo então para a discussão da capacidade do campo jurídico de regular, moldar, produzir, mediar, manter etc. as relações, os conflitos, os laços e os mundos sociais. Assim, busco problematizar a premissa de que os documentos devem representar ou refletir a realidade, tendo como referenciais autores como Foucault (1973), Bourdieu (1989) e Boltanski (1990). Defendo que esses documentos exercem um papel fundamental no processo de construção de verdades e, consequentemente, da realidade. 
Destarte, o primeiro documento que precisa ser analisado é o Relatório de Primeiro Atendimento, pois é esse que inicialmente materializa os sujeitos, transformando-os em assistidas/os do NUDIVERSIS. No campo desse relatório intitulado "resumo do caso" cristalizam-se não apenas as trajetórias das pessoas, mas também suas demandas e seus anseios. As narrativas contidas nesses espaços fabricam biografias que são desde muito cedo marcadas por uma sensação de incômodo em relação ao próprio corpo e ao gênero atribuído à/ao assistida/o em seu nascimento o que, segundo o Manual Diagnóstico e Estatístico de Transtorno Mentais (DSM), caracteriza um dos principais sintomas da "disforia de gênero". Reproduzo aqui um trecho de um desses relatórios para ilustrar o modo como tais indivíduos são construídos a partir da ênfase em determinados episódios de suas vidas.

Trata-se de resignação de nome. A assistida foi encaminhada pela Superintendência de Direitos Individuais, Coletivos e Difusos da SEASDH [Secretaria de Assistência Social e Direitos Humanos]. A assistida se identificou desde a infância como diferente das outras crianças do seu convívio social. Segundo a mesma, não se interessava pelas mesmas brincadeiras dos meninos, se identificando com as meninas. Aos 19 anos assumiu a transexualidade para a família passando a se vestir como mulher dentro e fora de casa e assumindo seu nome social, pelo qual se apresenta e é conhecida por seus amigos $e$ familiares. Afirma que obteve apoio de seu pai e de uma de suas irmãs. No entanto, o mesmo não ocorreu com sua mãe, a qual, por ser muito religiosa, não soube lidar com a situação.

Aos 23 anos começou a tomar hormônios femininos por conta própria, porém interrompeu a ingestão dos mesmos devido a efeitos colaterais, procurando orientação médica no HUPE [Hospital Universitário Pedro Ernesto], onde é acompanhada atualmente, apresentando interesse na cirurgia de readequação sexual.

A assistida apresenta como principal motivação para a mudança de prenome a possibilidade de plena convivência 
social, livre de preconceitos e das situações vexatórias pelas quais é submetida devido a atual discrepância entre a sua identificação física de gênero e o prenome constante do seu registro (Relatório de Primeiro Atendimento de Larissa ${ }^{6}$ ).

Outros documentos que constroem a realidade dos sujeitos são os laudos, atestados e declarações emitidos por profissionais da Medicina, principalmente psiquiatras. É a partir de uma dupla certificação conferida por esses papéis que as/os assistidas/os conseguem comprovar o "diagnóstico da disforia de gênero" condição tida como fundamental para o acesso a um dado conjunto de direitos. Ao mesmo tempo em que esses documentos atestam a rejeição e a negação de qualquer forma de identificação com o sexo atribuído ao nascimento, eles afirmam que a pessoa vivencia, "pensa como", "age de acordo com" $e$ "se identifica como pertencente" ao "gênero pleiteado".

Entretanto, apesar do caráter "patologizante" que os laudos $e$ atestados carregam, eles frequentemente funcionam como os únicos "passaportes" que permitem que pessoas transexuais consigam obter sucesso em atividades cotidianas como, por exemplo, realizar operações bancárias em que o documento de identificação é solicitado ou até mesmo viajar para fora do estado ou país. Tendo em vista que muitas vezes as pessoas transexuais, ao mostrarem seus documentos de identidade, têm sua veracidade questionada, a apresentação de um laudo de "disforia de gênero" pode ser um caminho para evitar maiores transtornos $e$ constrangimentos. ${ }^{7}$

Levo ao conhecimento deste serviço que a paciente [nome de registro] (nome social: Juliana), registro geral no HUPE $\mathrm{n}^{\circ} \mathrm{x}$ apresenta as condições previstas na Resolução $\mathrm{n}^{\circ} 1.958$ de 12 de agosto de 2010 do Conselho Federal de Medicina,

\footnotetext{
6 Todos os nomes citados ao longo do texto são fictícios.

${ }^{7}$ Agradeço ao professor Guilherme Almeida por, na ocasião da defesa da minha dissertação, sugerir que eu olhasse para esses laudos como "passaportes" que legitimam as pessoas transexuais a se moverem mais livremente pelos espaços.
} 
publicada no Diário Oficial da União em 03 de setembro de 2010, que dispõe sobre cirurgia de transgenitalização, ou seja:

a) tem o diagnóstico médico de transexualismo;

b) apresenta desconforto com o sexo anatômico natural;

c) exibe o desejo expresso de eliminar os genitais, perder as características primárias e secundárias do próprio sexo e ganhar as do sexo oposto;

d) o distúrbio permanece de forma contínua e consistente por mais de dois anos;

e) há ausência de outros transtornos mentais. (Encaminhamento interno do HUPE)

Interação com a imagem feminina: Patrícia veste-se como mulher, age como mulher, feminina e muito educada, possui um bom nível de aspiração com relação à vida pessoal e profissional. (Relatório psicológico da DPGE-RJ)

Declaro, para fins judiciários, que [nome de registro] (nome social: Camila) está em acompanhamento neste serviço com vista à futura cirurgia de transgenitalização por apresentar transexualismo. (Declaração psiquiátrica do HUPE)

Do mesmo modo que os Relatórios de Primeiro Atendimento, os laudos e relatórios de assistentes sociais que atuam junto às equipes que compõem os programas de saúde voltados para o atendimento de pessoas transexuais, no Programa Rio Sem Homofobia $(\mathrm{RSH})^{8}$ ou na DPGE-RJ, também sedimentam certas verdades sobre a trajetória das/os assistidas/os. Esses papéis também produzem itinerários biográficos específicos sobre os

8 O programa Rio Sem Homofobia (RSH), criado em maio de 2007, é uma iniciativa do Governo do Estado do Rio de Janeiro que tem por objetivo combater a discriminação e a violência contra a população LGBT e promover a cidadania desses sujeitos em todo o estado. O programa está vinculado à Secretaria de Assistência Social e Direitos Humanos do Governo do Estado do Rio de Janeiro (SEASDH/RJ) e é coordenado pela Superintendência de Direitos Individuais, Coletivos e Difusos (SuperDir). Para uma etnografia sobre o processo de construção e implementação do programa, consultar Aguião (2014). 
caminhos que levam à estabilização da identidade de gênero dos sujeitos, partindo de um momento inicial de questionamento do próprio sexo, passando pela busca da compreensão dos desejos, preferências e gostos experienciados e resultando em um processo de subjetivação, com o diagnóstico da transexualidade. Ademais, esses documentos apresentam, por um lado, as condições socioeconômicas nas quais as pessoas vivem (composição familiar, fontes de renda, condições de habitação etc.); e, por outro, as formas pelas quais elas exercem ou não a "cidadania". Além disso, também podem apresentar algumas recomendações, mais ou menos explícitas, direcionadas aos operadores do Direito, no sentido de defender a legitimidade do direito à alteração do registro civil.

A usuária Fernanda, sob o nome de registro [x], prontuário $\mathrm{n}^{\circ} \mathrm{x}$, é acompanhada por equipe multiprofissional (médicos urologistas, psiquiatra, serviço social e psicologia) do Hospital Universitário Pedro Ernesto, responsáveis pelo processo transexualizador no Estado do Rio de Janeiro. [...] A equipe de Serviço Social do programa em questão assiste a usuária durante todo o seu acompanhamento, [...] entende que é necessária e urgente a retificação de seu nome de registro, buscando interromper o intenso, contínuo e sistemático processo de constrangimento que vem lhe impedindo o livre acesso aos direitos básicos da cidadania. (Laudo social do HUPE).

Deseja ser reconhecida enquanto cidadã, participar da vida em sociedade como qualquer outra pessoa e não ser alijada. [...] Diante do exposto, percebeu-se que a usuária desde a sua adolescência luta por seu reconhecimento enquanto uma mulher $e$ a retificação do nome significa o exercício da cidadania, o qual a usuária tem direito. (Relatório social do RSH).

Gabriela tem sexo biológico masculino, mas desde muito cedo sempre se identificou com o sexo feminino. A usuária informa que iniciou o processo transexualizador em 2005 e 
que este se tornou mais concreto após adquirir sua prótese de silicone no ano passado. [...] Sendo assim, há anos que [nome de registro] não existe mais. Na verdade, esta pessoa jamais existiu, sendo apenas consequência de uma imposição da vida civil, que lhe impôs um sexo jurídico, o cárcere de sua identidade feminina (Relatório Social do RSH).

Os laudos, relatórios e atestados propiciados por psicólogos avaliam o estado mental dos indivíduos e, ainda mais importante, atestam tanto o desejo quanto o consentimento da/os assistida/o em relação aos efeitos não só das transformações corporais, mas também da requalificação civil. Assim como os laudos sociais, esses documentos também podem trazer recomendações em favor da requalificação civil. Contudo, as recomendações, por vezes, não se limitam aos operadores do Direito, direcionando-se também às/aos assistidas/os, como podemos ver em um dos exemplos a seguir:

A usuária apresenta discurso coerente e é ciente de todas as implicações decorrentes da retificação de nome. Em face ao exposto, solicito gentilmente que tais questões sejam levadas em consideração e que o referido seja retificado para que Clarice possa ter o resgate de sua autoestima $e$ melhoria em sua qualidade de vida (Relatório psicológico do $\mathrm{RSH})$.

Finalizando, caso deferidas as recomendações, é prudente que a entrevistada seja encaminhada a um tratamento psicoterápico individual, a fim de conhecer e entender melhor as dificuldades, emoções e constrangimentos que possam advir dessa etapa da transformação. Recomendação que foi acatada pela assistida (Relatório psicológico da DPGE-RJ).

Os outros três "tipos" de documentos que compõem as pastas das/os assistidas/os não podem ser aqui reproduzidos, os quais são: a lista de testemunhas, as fotografias $e$ as certidões emitidas pelos nove Ofícios de Registro de Distribuição (ORD) do 
Rio de Janeiro. Os primeiros são compostos, respectivamente, por nomes de pessoas e imagens das/os assistidas/os com amigos, familiares etc. e por isso, evidentemente, não podem ser expostos.

Para compor a lista de testemunhas, é preciso informar o nome completo, endereço residencial, telefone para contato $e$, eventualmente, o número de CPF de três pessoas. Tais pessoas devem estar dispostas a testemunhar em juízo, caso sejam chamadas a comparecer na audiência de requalificação civil. Em certa medida, essa lista funciona como um tipo de "contrato de fiança" no qual outros sujeitos auxiliam a produção da verdade com a assunção da responsabilidade pela veracidade dos relatos apresentados. Portanto, as/os assistidas/os são aconselhados a chamarem pessoas de sua confiança, que confirmarão a história apresentada na petição inicial e que responderão "corretamente" qualquer pergunta feita por juízes, promotores ou defensores. Contudo, é sugerido que não se chame familiares como testemunhas, pois, de acordo com a interpretação dos juízes, os laços de parentesco indicariam que as pessoas possuem "interesse na questão julgada", "contaminando" os depoimentos com interesses particulares e desvalorizando o testemunho destas pessoas.

As fotografias das/os assistidas/os, por sua vez, funcionam uma como uma espécie de "prova visual" do gênero, materializando "sujeitos generificados" por meio da performatividade (Butler, 2003). Como se pode imaginar, não é qualquer tipo de fotografia que pode ser entregue ao núcleo. Existem certas exigências que são passadas às/aos assistidas/os, dentre as quais estão: 1) a/o assistida/o não deve aparecer sozinha/o nas fotos; 2) elas/es devem estar em locais públicos; 3) é preciso que a foto retrate a "verdadeira identidade" de gênero da pessoa, ou seja, é preciso que ela esteja utilizando roupas, acessórios, cortes de cabelo etc. típicos do gênero com o qual se identifica. Esta última é a principal condição para que a foto seja aceita pelas profissionais do NUDIVERSIS e a única que, se não cumprida, implica sua rejeição. Diante desses critérios, faz sentido 
pensar que, nesse contexto, "ter passabilidade" 9 se configura como uma das condições para que o processo de requalificação civil possa ser instaurado. ${ }^{10}$

Já as certidões dos ORD, apesar de não conterem nenhuma informação pessoal que não possa ser omitida, trazem uma grande quantidade de tópicos analisados pelos funcionários, o que tornaria a leitura maçante. Por enquanto, limito-me a dizer que esses documentos atestam a inexistência de quaisquer pendências judiciais no nome de registro da/o assistida/o.

Em suma, é a partir de um diagnóstico, de uma assinatura e de um carimbo em relatórios, laudos, atestados, certidões etc. que as pessoas deixam de ser simplesmente pessoas e tornam-se portadores de uma "disforia de gênero", vítimas de discriminação, sujeitos sem pendências judiciais, assistidas/os da Defensoria Pública. Em outras palavras, esses papéis não refletem a realidade, mas a criam ativamente por meio de inscrições, ou seja, atos que produzem coisas que não estavam lá anteriormente ao mesmo tempo em que fixam e estabilizam os sentidos e significados atribuídos a determinadas experiências.

\section{Aquilo que pode ser registrado: a fabricação de "pessoas idôneas"}

O principal objetivo deste artigo é discutir como um conjunto de documentos é capaz de produzir a realidade. Entretanto, é preciso salientar que tais documentos não fabricam "quaisquer verdades" sobre os sujeitos. Busco agora refletir sobre quais verdades são produzidas por esses papéis. Todos os documentos que compõem as pastas das/os assistidas/os - exceto as cópias dos documentos de identificação - funcionam, em maior

9 A expressão "ter passabilidade" diz respeito ao fato de que, em algumas situações, uma pessoa transexual consegue "se passar por" uma pessoa cisgênero, isto é, por alguém cujo sexo/gênero designado ao nascimento condiz com aquele que o sujeito se identifica.

${ }^{10}$ Para uma análise mais detida do papel dos documentos e das fotografias na "certificação" do sexo/gênero de pessoas transexuais que demandam a requalificação civil, consultar Freire (2015b). 
ou menor grau, como peças na fabricação da idoneidade $e$ do sofrimento da pessoa e da verdade sobre a transexualidade. Argumento que tal fabricação depende, em parte, de um constante processo de contração e modulação das narrativas feitas pelas pessoas transexuais durante os atendimentos na Defensoria Pública.

Ao analisar os processos de requalificação civil em uma Promotoria Pública de Brasília, Teixeira (2013) salienta como as histórias eram escutadas a partir de um roteiro único. No cotidiano do NUDIVERSIS, a construção da semelhança dos relatos por meio de seleção e filtragem do que será documentado das narrativas tecidas pelas/os assistidas/os por parte das funcionárias do núcleo também se faz presente. Desse modo, aproprio-me e amplio a ideia de "convenção narrativa" utilizada por Nadai (2012) para refletir não somente sobre os modos de narrar passíveis de registro no cenário do núcleo, mas também para pensar sobre como determinadas "convenções" influenciam na maneira que os sujeitos relatam e descrevem suas experiências. Ao analisar uma série de documentos da Delegacia de Defesa da Mulher de Campinas, a autora postula que "convenções narrativas" são as formas pelas quais os relatos de experiências das pessoas podem se tornar inteligíveis em determinados contextos. Assim, uma biografia marcada por experiências de sofrimento $e$ constrangimento é compreendida como a primeira convenção narrativa que opera nos atendimentos realizados pelas profissionais do núcleo.

Elisa diz que nunca se sentiu gay e que ainda sente raiva quando alguém diz que ela é um "viado de saia"; afirma o tempo inteiro que age como uma "mulher normal", uma "senhora de respeito" e que não conseguiria, nem mesmo se tentasse, reproduzir os "trejeitos dos viadinhos". As travestis, por sua vez, são imediatamente associadas à prostituição, de modo que Elisa diz querer alterar seus documentos para poder ter um "emprego digno" e voltar à universidade "com a cabeça erguida". [...] A assistida conta que não se sentia nem gay e nem travesti, mas que nunca 
havia ouvido falar sobre transexualidade até ingressar no programa transexualizador do HUPE. Somente durante as consultas que ela adquiriu informações e passou a se identificar como transexual (Diário de campo, março de 2014).

Pedro relatou que foi casado durante nove anos com uma mulher, mas que não se sentia pleno. Em um dado momento, ele viajou para um sítio de uma amiga psiquiatra, que sugeriu que Pedro usasse as roupas do filho dela e passasse a se apresentar com um nome masculino. $\mathrm{O}$ assistido disse então que se sentiu muito feliz agindo desse modo. [...] Ele afirmou que não sabia nada sobre transexualidade e seu primeiro contato com o assunto se deu quando ele e uma amiga alugaram o filme "Meninos Não Choram"11 [Boys Don't Cry]. Segundo ele, assistir ao filme foi como se olhar no espelho (Diário de campo, maio de 2014).

A partir desses trechos, identifico outras duas convenções narrativas, ambas relativas à construção de subjetividade e à elaboração de uma "identidade transexual". A primeira delas busca reforçar a distinção entre a transexualidade e outras formas de significar as experiências dissidentes de identidade de gênero e orientação sexual, bem como das figuras que as representam: os homens gays, as mulheres lésbicas $e$ as travestis. Ao discutir a constituição da identidade transexual, Bento (2006) argumenta que o ato de dizer que "não é viado", "não é travesti" e "não é sapatão" representa a construção da identidade na e pela diferença.

Como pode ser visto nos relatos das/os assistidas/os $e$ trechos de diário de campo reproduzidos até aqui, todas essas

\footnotetext{
${ }^{11}$ O filme Meninos Não Choram, de 1999, dirigido por Kimberly Pierce, é baseado na história real de Brandon Teena, um homem transexual assassinado em uma pequena cidade do Estado de Nebraska, nos Estados Unidos. O caso de Brandon tornou-se emblemático para a militância LGBT estadunidense. Uma instigante análise não só sobre o filme, mas também sobre os arquivos do caso pode ser encontrada em Halberstam (2005).
} 
categorias muitas vezes são, nas interações cotidianas, colocadas sob os signos da homossexualidade ou da travestilidade. Em outras palavras, as pessoas transexuais continuam sendo socialmente identificadas como "viados", "sapatões" e travestis (Bento, 2006). Assim, a expressão "viado de saia" evidencia o alcance da performatividade na construção de uma identidade de gênero. Como apontado por Butler (1993), a produção de um gênero implica identificações com e rejeições de determinados atos performáticos, um processo que acarreta a construção de margens e fronteiras que delimitam o humano, criando assim uma matriz excludente. Desse modo, "viados", travestis e "sapatões" que habitam o espaço da abjeção conformam o "exterior constituinte" de uma identidade transexual que busca se estabelecer pela demarcação e hierarquização das diferenças.

O raciocínio da autora se complexifica quando ela oferece algumas respostas às críticas feitas ao seu primeiro grande trabalho sobre gênero: Gender Trouble, de 1990. Segundo Butler, uma leitura simplista de sua obra fez com que muitos acreditassem que ela definia o gênero como uma escolha livre e autônoma, baseada apenas na performance dos sujeitos. Em outras obras, Butler (1993, 2004) observa que os limites da invenção da performatividade é o olhar do outro, e é esse olhar que confere a materialidade dos corpos. Nesse sentido, os "corpos importam", pois é o corpo que oferece a matriz da performatividade de gênero possível, uma vez que é visto como uma espécie de "lugar" no qual as normas sociais são incorporadas e atualizadas.

A segunda convenção narrativa, que está intrinsecamente relacionada à primeira, diz respeito a um tipo de "tomada de consciência" que é promovido pelo contato com os discursos médico-científicos sobre transexualidade, seja por meio de filmes, reportagens, outras pessoas transexuais ou médicos e profissionais de saúde. Nesse sentido, perceber-se como transexual oferece uma estabilização, ao menos temporária, de uma identidade que confere sentido às suas experiências. Como consequência, tal percepção traz uma ressignificação dos eventos que compõem a biografia dos sujeitos. Como escreve Bento, 
[o] conhecimento da existência de outras pessoas que compartilham a mesma sensação de não-pertencimento ao gênero atribuído é relatado como um momento de "revelação" e de encontro. Finalmente, conseguem nomear; situar o que sentem; entender que não são os únicos com aqueles conflitos e, principalmente, que não são gays, travestis ou lésbicas. Ser "transexual" oferece uma posição identitária que dará um sentido provisório a suas vidas (Bento, 2006:209).

Assim, além de produzirem narrações compreensíveis, podemos pensar que as convenções narrativas estabelecem, em certa medida, os limites daquilo que pode ser falado, ouvido $e$ registrado. As fronteiras estabelecidas por essas convenções implicam, então, um constante processo de "contração narrativa", tendo em vista que nem tudo que é dito durante a entrevista de primeiro atendimento é anotado pela estagiária; nem tudo aquilo que é anotado é posteriormente descrito no Relatório de Primeiro Atendimento; e nem mesmo tudo aquilo que consta nesse relatório é transposto para a petição inicial. Em última instância, tais limitações funcionam para a construção de uma espécie de "homogeneidade experiencial" que cerca os modos de vida das pessoas transexuais.

Tal "homogeneidade experiencial" é fabricada na criação da figura de uma "pessoa idônea" por meio desses diferentes tipos de documentos. Como dito anteriormente, as testemunhas arroladas na petição inicial devem estar dispostas a confirmar todas as informações contidas na petição inicial, o que consiste em, basicamente, reforçar a condição de constante infortúnio da/o autora/or.

O extenso período da vida da/o assistida/o que é submetido à investigação - geralmente 20 anos - e a quantidade de assuntos verificados nas certidões emitidas pelos ORD - ainda que completamente dispensáveis em um processo de requalificação civil - sugerem que esses documentos não só comprovam a inexistência de pendências judiciais, mas também fazem parte da 
construção da imagem de uma pessoa idônea, merecedora do direito pleiteado. Sobre esse ponto, cabe destacar que existe uma discrepância entre os assuntos elencados pelas profissionais do NUDIVERSIS em seus encaminhamentos e os que são efetivamente analisados. São solicitadas certidões apenas sobre algumas matérias que são consideradas relevantes para o processo de alteração do registro civil, contudo, os funcionários dos Ofícios emitem documentos acerca de todas as questões que são responsabilidades da instituição. Tal disparidade não parece representar um problema. Pelo contrário, tendo em vista a economia de provas à qual as/os assistidas/os estão submetidas/os - que pode ser compreendida, grosso modo, como "quanto mais melhor" -, tais certidões, no modo como são escritas, possuem um imenso valor.

O caso de Elisa exemplifica como se dá a construção de "sujeito de direitos" que seja legítimo. Durante o atendimento, Elisa enfatizou sua vontade de fazer a cirurgia de transgenitalização para exercer sua sexualidade como, segundo ela, uma "mulher de verdade" - isto é, a penetração vaginal. No entanto, nada foi anotado sobre isso e não há nenhuma menção ao exercício da sexualidade em seu Relatório de Primeiro Atendimento ${ }^{12}$. Desse modo, podemos ver que o prazer e o desejo sexual não soam como motivos possíveis de figurarem nas petições iniciais escritas pelas profissionais do NUDIVERSIS. Como dito anteriormente, tais relatórios são caracterizados pela construção de trajetórias marcadas por sofrimento e martírio, e,

\footnotetext{
${ }^{12}$ A partir da comparação entre minhas anotações no diário de campo, as notas feitas pelas estagiárias durante o primeiro atendimento e as informações contidas no Relatório de Primeiro Atendimento, é possível perceber que a produção desses diferentes documentos deve ser apreendida como um processo por meio do qual as narrativas dos sujeitos são reduzidas e traduzidas para uma linguagem juridicamente tanto compreensivel quanto aceitável. Contudo, ressalvo que não tomo as diferenças entre as três modalidades de registrar narrativas de forma ingênua ou hierárquica. Apesar de, grosso modo, todas elas terem por função produzir uma espécie de memória, elas possuem finalidades, interesses $e$ linguagens muito distintas, o que afeta sua constituição desde o início.
} 
por vezes, pela superação de obstáculos, como podemos ver no seguinte exemplo:

A assistida era constantemente transferida de setor e sofria acusações infundadas, como, por exemplo, um boato acerca de Selma ter assediado um rapaz e a mãe desse rapaz ter formulado uma queixa junto à administração da [empresa]. [...] Por fim, Selma cedeu à pressão e pediu demissão. A partir daí, Selma teve dificuldade em conseguir outro emprego devido a divergência entre seus documentos pessoais e sua aparência. Selma então mudou-se para a casa de amigos, que a apoiaram e ajudaram-na a se requalificar no mercado de trabalho. A assistida trabalhou como faxineira e cabeleireira para manter seu sustento. [...] Nem mesmo sua qualificação profissional venceu os obstáculos empregatícios impostos por sua aparência feminina e Selma continuou desempregada. Seguindo o conselho de seus "irmãos", Selma decidiu prestar concurso público. A assistida foi bem sucedida em sua empreitada e foi aprovada no concurso para [cargo e instituição]. Após tomar posse, foi aprovada também no concurso de [cargo e instituição], optando por esse último. (Relatório de Primeiro Atendimento de Selma)

Os laudos dos psiquiatras e psicólogos atestam o desconforto do indivíduo em relação ao seu próprio corpo, enquanto os assistentes sociais comprovam como a vida das/os assistidas/os é marcada por experiências de constrangimento $e$ discriminação que geram incessantes sofrimentos, demandando, assim, que algo seja feito por essas pessoas.

É necessária e urgente a retificação de seu nome de registro, buscando interromper o intenso, contínuo $e$ sistemático processo de constrangimento que vem lhe impedindo o livre acesso aos direitos básicos da cidadania (Laudo social do HUPE).

Atualmente trabalha na empresa [nome], onde é necessário a utilização de seu nome para todos os processos de 
intervenção, gerando assim situações de extremo constrangimento, expondo a vida íntima da usuária. Tem sido utilizado o nome de registro em sua apresentação na empresa (Relatório social do RSH).

Os relatórios psicológico e social que compõem o Estudo Social avaliam a procedência do pedido de requalificação civil na medida em que também reforçam essa visão das/os assistidas/os como sujeitos a um incessante sofrimento psíquico e social causado pelos episódios de constrangimento e discriminação.

As fotografias, ainda que não atestem o sofrimento, também possuem um importante papel na fabricação da idoneidade. No contexto de uma "economia de suspeição", essas fotos servem para comprovar que os indivíduos que demandam a requalificação civil são "verdadeiramente transexuais" (Bento, 2006), e não estão tentando se aproveitar de uma exceção da regra de "imutabilidade do prenome" para "fins ilícitos", uma vez que demonstram que eles "vivem publicamente o gênero pleiteado".

Das pessoas que fazem documentos: entre assinaturas e carimbos, ou o papel da autoridade na produção da verdade

[...] já para as transexuais o caminho é mais fácil, acaba sendo mais fácil porque juiz gosta de laudo, de documento, de atestado, de papel. Aí tem um psicólogo, um psiquiatra, um urologista, um monte de profissional que faz um documento dizendo que é transexual, que quer fazer cirurgia, eles acham ótimo e com isso eles dizem "ah, então pode mudar o nome" porque é transexual (entrevista com a defensora pública, grifos meus).

Apesar de tratar de forma mais ou menos genérica os diversos tipos de documentos localizados nas pastas das/os assistidas/os do NUDIVERSIS, saliento que é preciso distinguir o "peso" ou "valor" de cada um deles, uma vez que possuem propriedades de verdade distintas entre si. Isto é, esses 
documentos atestam verdades sobre diferentes aspectos da vida dos sujeitos, os quais, de acordo com a economia de provas que cerca o processo de requalificação civil, são considerados mais importantes que outros.

Busco, então, demonstrar como os documentos são diferentemente valorados $e$ hierarquizados nos pedidos de requalificação civil de pessoas transexuais, ainda que todos sejam classificados como indispensáveis pelas funcionárias do núcleo. Como é possível perceber a partir da fala da defensora pública reproduzida acima, as "provas técnicas" - isto é, aqueles documentos que possuem assinaturas e carimbos, que são certificados por alguma autoridade competente, detentora de um saber característico - ocupam uma posição de maior prestígio que aqueles que são produzidos pelas/os próprias/os assistidas/os, como as fotografias e a lista de testemunhas.

É nesse sentido que inverto o enunciado que dá título à primeira seção do texto: de "documentos que fazem pessoas" para "pessoas que fazem documentos". Logo, minha preocupação aqui é menos como os documentos fabricam e sedimentam verdades sobre os sujeitos e mais como determinados indivíduos são considerados como dotados do poder de produzir a verdade por meio da escrita, tornando outras pessoas inteligíveis por meio desse processo.

Bourdieu (1989) utiliza a expressão "linguagem autorizada" para dar conta da articulação entre poder, autoridade, discurso $e$ produção da verdade. De acordo com essa noção, o poder não se encontra no discurso em si, mas está ancorado no reconhecimento e na legitimação do sujeito que pronuncia o discurso. Essa articulação pode ser encontrada, por exemplo, no campo do Direito. Para o autor, não é qualquer pessoa que pode falar sobre "direitos", pois as falas possuem valores distintos e é preciso um domínio da linguagem utilizada.

A autoridade de determinados profissionais foi trabalhada também por Fassin e Rechtman (2009) em sua pesquisa sobre a construção da noção de "trauma". Os autores chamam atenção para a necessidade da produção dos laudos por "mediadores 
especialistas" - no caso, psiquiatras e psicólogos - para que se concretize a figura do indivíduo traumatizado. Esses especialistas possuem o poder de escrutínio da verdade de um sofrimento que não é evidente, pois não é localizável no corpo, mas sim na psique.

Detenho-me um pouco mais na obra de Fassin e Rechtman por conta das apropriações possíveis para a análise do contexto do NUDIVERSIS. Como dito anteriormente, os psiquiatras $e$ psicólogos são aqueles que possuem o capital simbólico necessário para a transformação do sofrimento em "direitos". Essa metamorfose é efetivada por meio da inscrição e da tradução do dano sofrido pelo sujeito em um laudo que atesta o trauma. Entretanto, o reconhecimento do sofrimento não implica uma relação imediata com um direito de reparação, existindo sempre uma margem de incerteza que perpassa a politização do sofrimento.

Guardadas as devidas proporções, situo as profissionais da Defensoria Pública como "mediadoras especialistas" que efetuam uma espécie de "metatradução". O primeiro movimento de atribuição de significados é feito pelos psiquiatras, os quais transformam as experiências dos sujeitos em uma patologia codificada - "disforia de gênero", F64.0 - por meio da emissão de um laudo, um papel devidamente assinado e carimbado. Concomitante ao surgimento dessa categoria nosológica, aparece seu respectivo tratamento: a "terapia de mudança de sexo", a qual inclui, no plano das intervenções corporais, a ingestão de determinados hormônios e uma série de cirurgias, sendo a mais importante a de transgenitalização; e no plano jurídico, a alteração de nome e sexo no registro civil. Uma vez de posse desses laudos, cabe às operadoras do Direito efetivar uma segunda transformação para fazer com que as prescrições médicas se tornem compreensíveis na linguagem jurídica, criando, nesse processo, as pessoas transexuais como "sujeitos de direitos específicos". 
Papéis mágicos: sobre documentos, performatividade $e$ atos de magia

Explorei até aqui como os documentos presentes nas pastas das/os assistidas/os operam um "fazer existir" da pessoa transexual. De certo modo, esses papéis são registros visuais - no caso das fotografias - e impressos de atos performáticos que constroem os sujeitos em seus múltiplos aspectos. Tendo em vista que possuem um poder próprio de materializar não apenas os sujeitos, mas também as relações que os constituem enquanto tal, sugiro que os documentos sejam encarados em si mesmos como "objetos performativos" oriundos de "atos mágicos". A proposição da ideia de "objeto performativo" parte de apropriações $e$ aproximações das teorias de Mauss (2003) sobre magia e atos mágicos, e das noções de "performatividade" de Butler (1993, 2003) e de "ritos de instituição" de Bourdieu (1996).

Para Butler, performatividade e materialidade são elementos intrinsecamente ligados. A "materialidade dos corpos" não é senão o efeito de um poder produtivo e o resultado de atos performativos. Nas palavras da autora, "a performatividade deve ser compreendida não como um 'ato' singular ou deliberado, mas, em vez disso, como a prática reiterativa e citacional pela qual o discurso produz os efeitos que ele nomeia" (Butler, 1999:154). Logo, mais do que retratar e descrever, esses documentos funcionam como elementos que produzem pessoas.

Esse poder de fabricação da realidade que os documentos têm é inegavelmente dependente da crença que são capazes de criar, reforçar, modificar e desfazer mundos sociais. É essa mesma crença que sustenta a promessa de "transformação de homens em mulheres" e vice-versa que perpassa toda a visão da "terapia de mudança de sexo" como a "cura" para a "disforia de gênero", que tem na cirurgia de transgenitalização e na subsequente alteração do registro civil seu ápice, permitindo que a pessoa reconstrua e recomece sua vida "do zero" e de acordo com sua "verdadeira identidade". A disseminação e a presença dessa crença - $e$ também promessa - podem ser percebidas a partir dos seguintes fragmentos: 
Conforme relato da usuária, a retificação de nome representa o seu renascimento, o começo de uma vida sem preconceito, discriminação e violência no convívio social devido sua aparência feminina $e$, principalmente, a necessidade de utilizar legalmente o nome masculino (Relatório Social do RSH).

Durante o primeiro atendimento de Marta, me chamou atenção a narrativa da assistida sobre o relacionamento com sua família. Ela contou que nenhum de seus familiares a chama pelo seu nome social e que ela compreende a atitude deles, uma vez que ela ainda não "trocou seus documentos". A mesma situação se repete em seu trabalho. De um modo geral, Marta disse que evita se apresentar pelo seu nome social em situações que ela acredita que serão constrangedoras (Diário de campo, maio de 2014).

Se considerarmos que esses documentos possuem o poder de criar e definir o que é real e o que não é - ou ainda, o que é verdade e o que não é - e que tal poder é oriundo de uma crença socialmente compartilhada, proponho que esses papéis sejam pensados a partir do seu caráter "mágico" e que as ações que os produzem sejam vistas como "atos de magia" (Mauss, 2003).

Desse modo, os movimentos executados pelas pessoas transexuais em sua busca por direitos - ou seja, as consultas com psicólogos, psiquiatras e endocrinologistas, as entrevistas com assistentes e as solicitações aos funcionários dos ORD - constituem atos mágicos rituais que, ao serem executados por uma autoridade, constroem uma dada realidade. De acordo com Bourdieu (1996), é a partir da linguagem autorizada que os atos e ritos de instituição - isto é, de nomeação, categorização etc. - se configuram como uma espécie de "magia performativa do ritual". Em outras palavras, tais atos representam o poder das palavras de não apenas descrever algo existente, mas instituir realidades a partir do discurso, corroborando para a hipótese de enxergar esses papéis como peças dotadas de poderes mágicos. 
Algumas das ideias discutidas por Mauss (2003) são fundamentais para a compreensão do raciocínio aqui proposto, especialmente se levarmos em consideração que o que sustenta o poder dos "artigos mágicos" é a crença na sua capacidade de fazer efetivamente aquilo a que se propõem $e$ a materialidade adquirida após os atos mágicos, representada, no caso, pelos documentos. Para Mauss (2003), três são os elementos constituintes da magia: 1) os "agentes", aqueles que executam os atos mágicos; 2) os "atos", ou ritos mágicos que funcionam como um tipo de linguagem através da qual as ideias são traduzidas; e 3) as "representações", o sentido adquirido pelo rito mágico. A partir desses elementos, a magia é encarada então como um fenômeno indiscutivelmente social, pois depende fundamentalmente, por um lado, da crença de seus praticantes na sua eficácia e veracidade e, por outro, da materialidade dos atos mágicos. Outra observação do autor que precisamos levar em consideração é sobre a aproximação entre magia e ciência. Mauss demonstra em diversos pontos do seu texto o evidente parentesco entre as duas ideias, uma vez que o "êxito científico" também depende da crença dos sujeitos no seu funcionamento, desfazendo assim uma visão que opõe as duas coisas.

A partir dessas colocações, sugiro que pensemos nos diversos profissionais envolvidos nos processos de requalificação civil, ou seja, psiquiatras, psicólogos, endocrinologistas $e$ assistentes sociais - todos dotados de um conhecimento científico que autoriza o exercício do poder - de modo semelhante ao utilizado por Mauss para descrever os mágicos. Ambos, mágicos e cientistas (ou profissionais), produzem algo - ou seja, dão materialidade a alguma coisa - que não existia antes, por meio de algum tipo de encantamento ou ato mágico.

Apesar de não ser o objeto privilegiado da investigação empreendida, a produção dos sujeitos por essa série de mágicosprofissionais pode ser condensada na sentença proferida por um juiz após o julgamento do processo de requalificação civil. Quando o pedido é julgado procedente, tal sentença é encarada como um marco do surgimento de uma nova pessoa, como mencionado por 
várias/os das/os assistidas/os do núcleo. Trago agora um trecho de uma sentença que exemplifica o que estou chamando de "ato mágico":

Decido. Cuida-se de requerimento de retificação de registro civil de nascimento, para substituir o nome masculino que ali conste Daniela. O pedido foi devidamente instruído com documentos médicos que atestam a condição de transexual do requerente, o qual, sendo anatomicamente do sexo masculino, apresenta personalidade inversa, ostentando, desde a infância, comportamento feminino, encontrando-se feliz com a nova condição física, mas vive recolhido sob o temor de vir a ter que identificar-se com seus documentos masculinos, sofrendo grande constrangimento. Cuidando-se de procedimento de jurisdição voluntária, não houve impugnação ao pedido e o Ministério Público opinou favoravelmente. [...] Isto posto, defiro o requerimento, para determinar a retificação do assento de nascimento da requerente, com substituição do prenome $[\mathrm{x}]$ para constar Daniela, permanecendo as demais anotações (sentença do processo de requalificação civil de Daniela).

Assim, seguindo de perto as ideias de Mauss, identifico no processo de fabricação das "provas técnicas" os mesmos elementos que compõem a magia: os "agentes" (psicólogos, psiquiatras, assistentes sociais, funcionários de instituições estatais, etc.), por meio de "atos mágicos" (consultas, entrevistas, verificação de arquivos) apoiados em certas "representações" (autoridade profissional, definição médica da transexualidade, normativas legais), produzem determinados documentos que funcionam como "objetos performativos", isto é, papéis com poderes para definir e certificar o gênero, as condições psíquicas, a idoneidade, dentre outros aspectos da vida dos indivíduos.

Por fim, reconheço que, em um primeiro momento, a conexão entre as ideias de "performatividade" e "magia" para compreender como documentos possuem a capacidade de produzir corpos, realidades e sujeitos parece não ser necessária para dar conta do argumento exposto, uma vez que, para Mauss, 
a eficácia da magia depende muito mais da crença que da materialidade, ao passo que o conceito de performatividade de Butler não é pensado como tendo algum tipo de componente mágico. Entretanto, acredito que, nos casos de requalificação civil, pensar no caráter ao mesmo tempo mágico e constitutivo desses documentos faz sentido não porque eles são construídos como capazes de desafiar ou pôr em xeque concepções de "sexo biológico" fortemente arraigadas no senso comum - isso seria fazer coro com uma noção, também presente no senso comum, de que a magia é algo fantasioso, inexistente e capaz de operar atos inacreditáveis; mas sim porque, como já mencionado, todos os procedimentos que compõem a "terapia de mudança de sexo" são sustentados por teorias médico-científico-jurídicas que são inquestionáveis e não podem ser "desfeitos".

Para tentar deixar meu raciocínio mais claro, trago o caso de Raissa de um modo um tanto resumido. Raissa era uma mulher transexual que havia obtido a alteração de seu nome em seus documentos civis. Após alguns meses, ela retornou ao NUDIVERSIS para obter seu nome masculino de volta, pois, segundo ela, os novos documentos não trouxeram nenhuma mudança no seu cotidiano, ela continuava sofrendo uma série de discriminações por ser uma mulher transexual. Diante disso, Raissa afirmou que gostaria de "voltar a ser menino" porque "a vida de gay é mais fácil que a vida de transexual". Desde o primeiro momento, a demanda por "reversão do processo de requalificação civil" não foi aceita pelas funcionárias do núcleo, que formularam diversos argumentos para que Raissa desistisse da ideia de alterar novamente seu registro civil, bem como justificativas para recusar tal demanda, dentre elas, a de que Raissa encontrava-se em um "estado depressivo" e não tinha a autonomia necessária para tomar uma decisão desse tipo.

De um modo geral, todas as ações adotadas pelas profissionais do NUDIVERSIS estavam previstas e/ou foram baseadas nas normativas contidas na "terapia de mudança de sexo". Como salienta Mauss (2003), quando a magia dá errado, a crença protege a magia de ser questionada e atribui ao mágico a 
responsabilidade pela falha. Quando a "terapia de mudança de sexo" não funciona, a autoridade médico-científica impede que o "tratamento" seja contestado, pois, uma vez que o "problema" é transferido para a pessoa transexual - afinal, o "problema" é a "disforia de gênero", e não as normas sociais (Teixeira, 2013) -, somente ela mesma pode ser considerada como responsável pelo insucesso da "terapia".

Considerações finais: a composição do mosaico e o "acesso aos direitos"

Ao longo deste artigo, foram abordadas duas ideias principais sobre os documentos: 1) seu potencial de construção da realidade e não mera representação ou reflexo; 2) o papel de determinadas autoridades profissionais na produção dos documentos e, consequentemente, da realidade. Para encerrar, busco discutir como esses papéis se articulam para a produção de uma espécie da "homogeneidade experiencial", como sinalizado anteriormente, e de que modo são determinantes para o "acesso aos direitos".

Uma vez que estão inseridos em uma economia jurídicomoral que regula o "acesso aos direitos", o principal objetivo desses documentos é a produção da única figura legítima a pleitear as alterações do nome e do sexo no registro civil: um sujeito idôneo que, por ser portador de um transtorno, configurase como uma vítima que precisa e merece ter seu sofrimento aliviado. Afirmo que essa produção se faz por meio da constante negação de aspectos que remetem ao que é discursivamente fabricado como um espectro que ronda os processos de requalificação civil: a/o falsa/o transexual (Bento, 2006). É esse intento de configurar a pessoa "verdadeiramente transexual" que acarreta na constante eliminação $e$ apagamento das múltiplas possibilidades de leitura $e$ interpretação das experiências da transexualidade, assim como de uma série de outros marcadores sociais, tais como raça e classe.

Os laudos, apesar de serem considerados os mais importantes, não são os únicos documentos necessários para a 
instauração da ação de requalificação civil, pois eles só podem atestar verdades sobre determinadas áreas da vida de um indivíduo. Ressalvo, então, que psicólogos e psiquiatras são autorizados a falar somente sobre as condições psíquicas de uma pessoa; endocrinologistas proporcionam atestados referentes apenas à "vida hormonal" dos sujeitos; assistentes sociais descrevem a situação socioeconômica na qual o indivíduo vive $e$ também as formas pelas quais ele consegue ou não exercer a cidadania; tabelióes e funcionários dos ORD comprovam a existência ou não de registros oficiais em nome da/o assistida/o; as testemunhas são chamadas a comprovar a veracidade da biografia; e, por último, as fotografias completam a constituição do sujeito ao oferecerem uma imagem que servirá para ancorar todas as outras "verdades".

Desse modo, é possível pensar como a "verdade" dos sujeitos - e no caso da administração pública do direito à requalificação civil de pessoas transexuais o que está em jogo é a "verdade da transexualidade" - se distribui por diversos aspectos: ela está na psique, na corporalidade, na performance, nas relações familiares, nos vínculos empregatícios etc. Considerando essa distribuição, sugiro que os sujeitos dos quais esses papéis falam devem ser vistos como um mosaico: uma imagem constituída por peças de diferentes tamanhos, mas que são complementares, pois somente quando todas se encontram reunidas é que a figura se torna evidente e pode ser percebida em sua totalidade. Contudo, não basta que todos os pedaços estejam juntos, eles precisam estar corretamente dispostos e encaixados para que a imagem não fique distorcida ou ambígua. Uma imagem que não seja suficientemente clara e coerente abre espaço para dúvidas acerca de sua compreensão, uma vez que é possível ver coisas distintas daquilo que era pretendido por quem a montou.

Em outras palavras, mais do que produzir sujeitos, esses papéis constroem uma figura de mosaico muito específica, que possui um dado gênero (aquele que é pleiteado na ação de requalificação civil), uma certa índole (alguém que não possui nenhuma pendência para com a "sociedade") e uma determinada 
biografia (uma pessoa que passou e passa por constantes episódios de constrangimento e discriminação, gerando assim um sofrimento incessante). Desse modo, laudos, certidões, relatórios etc. são peças que - por meio de processos mágicos-performativos - classificam e constituem sujeitos de acordo com uma certa matriz de entendimento, permitindo que somente "sujeitos legítimos", ou seja, as/os "verdadeiras/os transexuais" (Bento, 2006) tenham acesso a um conjunto de direitos, tanto no âmbito da saúde - tais como as cirurgias de retirada de mamas e do útero, a transgenitalização, a aquisição gratuita de hormônios e o acompanhamento necessário à sua administração - quanto no âmbito jurídico - a alteração de nome e/ou sexo no registro civil.

\section{Referências bibliográficas}

AGUIÃO, Silvia. Fazer-se no "Estado": uma etnografia sobre o processo de constituição dos "LGBT" como sujeitos de direitos no Brasil contemporâneo. Tese (Doutorado em Ciências Sociais), Unicamp, Campinas, 2014.

BEnTo, Berenice. A Reinvenção do Corpo: sexualidade e gênero na experiência transexual. Rio de Janeiro, Garamond, 2006.

BOLTANSKI, Luc. El Amor y la Justicia como competencias: tres ensayos de la sociología de la acción. Buenos Aires, Amorrortu, 1990.

BOURDIEU, Pierre. A Força do Direito: elementos para uma sociologia do campo jurídico. In: . O Poder Simbólico. Lisboa/Rio de Janeiro, Difel/Betrand Brasil, 1989, pp.209-254.

. A Economia das Trocas Linguísticas: o que o falar quer dizer. São Paulo, EDUSP, 1996.

ButLER, Judith. Bodies That Matter: on the discursive limits of "sex". Nova Iorque, Routledge, 1993.

. Corpos que pesam: sobre os limites discursivos do 'sexo'. In: LOURO, Guacira Lopes (org.). O Corpo Educado: pedagogias da sexualidade. Belo Horizonte, Autêntica, 1999, pp.151-172.

Problemas de Gênero: feminismo e subversão da identidade. Rio de Janeiro, Civilização Brasileira, 2003. 
. Undoing Gender. Nova Iorque, Routledge, 2004.

FASSIN, Didier; RECHTMAN, Richard. The Empire of Trauma: an inquiry into the condition of victimhood. Princeton, Princeton University Press, 2009.

FERREIRA, Letícia. Uma etnografia para muitas ausências: o desaparecimento de pessoas como ocorrência policial e problema social. Tese (Doutorado em Antropologia Social), UFRJ, Rio de Janeiro, 2011.

Foucault, Michel. A Verdade e as Formas Jurídicas. Rio de Janeiro, NAU, 1973.

FREIRE, Lucas. A Máquina da Cidadania: uma etnografia sobre a requalificação civil de pessoas transexuais. Dissertação (Mestrado em Antropologia Social), Museu Nacional/UFRJ, Rio de Janeiro, 2015a.

. Certificações do Sexo e Gênero: a produção de verdade nos pedidos judiciais de requalificação civil de pessoas transexuais. Mediaçôes (20), Londrina-PR, Programa de Pós-Graduação em Ciências Sociais-UEL, 2015b, pp.89-107.

HALBERSTAM, Judtih/Jack. In a Queer Time and Place: transgender bodies, subcultural lives. Nova Iorque/Londres, New York University Press, 2005.

MAUSS, Marcel. Esboço de uma teoria geral da magia. In: Sociologia e Antropologia. São Paulo, Cosac Naify, 2003, pp. $\overline{47-181}$.

MirAndA, Ana Paula. Fiscos e Cartórios: exemplos de burocracia à brasileira. In: SoUZA LIMA, Antonio Carlos (coord.). Antropologia e Direito: temas antropológicos para estudos jurídicos. Rio de Janeiro/Brasília, Contra Capa/ LACED/ABA, 2012, pp.276-285.

SchritzMeyer, Ana Lúcia Pastore. Introdução do Eixo Direito aos Direitos. In: SouZA LIMA, Antonio Carlos de (coord.). Antropologia e Direito: temas antropológicos para estudos jurídicos. Rio de Janeiro/Brasília, Contra Capa/ LACED/ABA, 2012, pp.262-270.

TEIXEIRA, Flávia. Dispositivos de Dor: saberes-poderes que (con)formam as transexualidades. São Paulo: Annablume/FAPESP, 2013.

VIANNA, Adriana. Atos, Sujeitos e Enunciados Dissonantes: algumas notas sobre a construção dos direitos sexuais. In: MILSKOLCI, Richard; 
Pelúcio, Larissa (orgs.). Discursos Fora da Ordem: sexualidades, saberes e direitos. São Paulo, Annablume, 2012, pp.227-244.

- Etnografando documentos: uma antropóloga em meio a processos judicias. In: CASTILHO, Sérgio; SouZA LimA, Antonio Carlos; TeIXEIRA, Carla Costa (orgs.). Antropologia das Práticas de Poder: reflexóes etnográficas entre burocratas, elites e corporaçóes. Rio de Janeiro, Contra Capa/FAPERJ, 2014, pp.43-70.

WEBER, Max. Sociologia do Direito. In: . Economia e Sociedade: fundamentos da sociologia compreensiva, vol. II. Brasília/São Paulo, Editora da UNB/ Imprensa Oficial do Estado de São Paulo, 1999, pp.1-153. 